\title{
Case report on toxicity of methotrexate in tubal ectopic pregnancy
}

\author{
Surbhi Lodha*, Kimaya Mali \\ Department of Obstetrics and Gynecology, G. S. M. C. and KEM Hospital, Mumbai, Maharashtra, India
}

Received: 19 April 2020

Accepted: 29 May 2020

\section{*Correspondence:}

Dr. Surbhi Lodha,

E-mail: surbhig11992@gmail.com

Copyright: $\odot$ the author(s), publisher and licensee Medip Academy. This is an open-access article distributed under the terms of the Creative Commons Attribution Non-Commercial License, which permits unrestricted non-commercial use, distribution, and reproduction in any medium, provided the original work is properly cited.

\section{ABSTRACT}

Ectopic pregnancy is defined as pregnancy outside uterine cavity. Of all ectopic pregnancy, tubal ectopic is most common. Most cases today are diagnosed early and hence timely treatment is possible. In stable patients, medical line of management with methotrexate can be used. With early diagnosis and medical line of treatment, use of injectable methotrexate is on rise. Being aware of characteristics of methotrexate like mechanism, dosage, side effects and contraindications, appropriate patient selection and watchful monitoring will help reduce methotrexate induced toxicity.

Keywords: Contraindication, Methotrexate, Side effects, Tubal ectopic pregnancy

\section{INTRODUCTION}

Ectopic pregnancy is defined as pregnancy outside uterine cavity. Of all ectopic pregnancy, tubal ectopic is most common. Most cases today are diagnosed early and hence timely treatment is possible. In stable patients, medical line of management with methotrexate can be used. With early diagnosis and medical line of treatment, use of injectable methotrexate is on rise. Being aware of characteristics of methotrexate like mechanism, dosage, side effects and contraindications, appropriate patient selection and watchful monitoring will help reduce methotrexate induced toxicity.

\section{CASE REPORT}

G3P2L2, aged 21 years, visited a private hospital in view of per vaginal bleeding since 1 month. Patient has 1 male and 1 female child of 3 years and 1 and half year old, both by caesarean sections at term. Urine pregnancy test was positive. On examination patient was vitally stable. The gynecologists advised an ultrasound abdomen and pelvis. Ultrasound was suggestive of $1.1 \mathrm{~cm}$ well defined cystic structure corresponding to 6 weeks gestation seen in anterior myometrium in region of LSCS scar. There was no yolk sac or fetal pole. Uterus was measuring $7 \times 4.3 \times 4.2 \mathrm{~cm}$ with bilateral ovaries normal size. Ultrasound was suggestive of LSCS scar pregnancy. On reviewing the ultrasound and initial blood investigation, 3 doses of $50 \mathrm{mg}$ inj. methotrexate was given intravenously to patient on 3 consecutive $\mathrm{d} 2, \mathrm{~d} 3$ and $\mathrm{d} 4$ of admission. On being discharged on $\mathrm{d} 4$, patient developed glossitis and scaly skin lesions on $\mathrm{d} 6$ at home.

Patient went to maternity home nearby, was diagnosed Steven Johnson syndrome secondary to methotrexate. Patient was given injection leucovorin 15 microgram for 10 doses and inj. methylprednisolone single dose. On day 3 of admission at maternity home, even though the skin reactions improved, the patient started developing fever and pancytopenia with WBC 600. Patient was then transferred to tertiary care center and admitted in intensive care unit. On admission, general condition of patient was poor, though she was conscious, oriented. Multiple scaly lesions over face, limbs, extensive glossitis was present, severe enough to cause bleeding on touch. Patient was unable to talk due to painful oral lesions. Pulse was $92 \mathrm{bpm}$, bp $120 / 70 \mathrm{mmHg}$. Per abdomen examination revealed no tenderness, guarding or rigidity. On per vaginal examination uterine size was 
bulky, non-tender, anteverted, bilateral fornices were nontender and free. Blood investigations revealed bicytopenia, $\mathrm{Hb} 8.9$, WBC $600 / \mathrm{mm}^{3}$. Urine routine showed $2+$ protein and $3+\mathrm{RBC}$ with 24 hours urine protein 828 $\mathrm{mg}$ and CRP $>150 \mathrm{mg} / \mathrm{dl}$. Patient was diagnosed as bicytopenia with superimposed acute kidney injury with Steven Johnson syndrome secondary to methotrexate in case of caesarean scar ectopic pregnancy. Ultrasound done was suggestive of $\mathrm{G} \mathrm{sac}$ without fetal pole or yolk sac at site of scar, $1 \times 0.5 \times 0.5 \mathrm{~cm}$ with peripheral vascularity. Dermatology and hematology opinions was taken along with medical and gynecology treatment. Patient was started on intravenous antibiotics and analgesia. According to hematologist advice, patient was started on inj. GSF (Granulocyte stimulating factor) for 3 days till absolute neutrophil count $>1500$. Also, patient was started on Momate cream for limb ulcers and scaling. $\mathrm{KMnO}_{4}$ gargles, normal saline soaks for lip lesions, oral mucopaine gel and candid mouth paint. For genital lesions patient was given local fusidic acid cream. After completing 5 days of GSF injection the $\mathrm{CBC}$ report showed $\mathrm{Hb} 8.4$, WBC $4400 / \mathrm{mm}^{3}$, absolute neutrophil count of $56 / 100$ cells, and platelet $1 \mathrm{lakh} / \mathrm{mm}^{3}$. Patient was symptomatically better by $\mathrm{d} 6$ of admission, WBC were in rising trend and urine routine did not show proteinuria. Patient was continued on conservative management under supervision of hematologist and dermatologist. Regular $\beta$ hcg was done for patient which was in decreasing trend. Patient, though recovered from scaly ulcerative lesions, but did have excessive hair fall secondary to methotrexate. After a total stay for 14 days, patient recovered almost all the skin lesions. In view of decreasing hcg patient was managed conservatively by gynecologist. On day of discharge, CBC was normal and $\beta$ hcg was 476 . On follow up in on $\mathrm{d} 22$ of tertiary center admission, hcg decrease to less than 5. Methotrexate has done wonders in the field of gynecology but vigilant use is more important to avoid such serious side effects.

Table 1: Blood parameters on respective day of admission in hospital.

\begin{tabular}{|llll|}
\hline Parameters & D1 & D3 & D6 \\
\hline Hemoglobin & 10.0 & & 8.9 \\
\hline RBC & & & 3.51 \\
\hline PCV & & & 27.2 \\
\hline Total leucocyte count & 600 & & 5600 \\
\hline Platelet count & 274000 & & 102000 \\
\hline BUN & 8.6 & 8.50 & \\
\hline Creatinine & 0.7 & 0.5 & \\
\hline Na+ & 134 & 132 & \\
\hline K+ & 4.17 & 4.04 \\
\hline Total protein & 7.19 & & \\
\hline Albumin & 3.88 & & \\
\hline Globulin & 3.31 & & \\
\hline Bilirubin & 0.48 & \\
\hline SGOT & 287 & \\
\hline SGPT & 16 & \\
\hline Alkaline phosphatase & 73 & \\
\hline Glucose & 109 & \\
\hline
\end{tabular}

Table 1 shows the trend of haemoglobin and total leucocyte count. Initially the patient presented with bicytopenia with low haemoglobin and leukopenia secondary to methotrexate toxicity. Although platelet count remained normal. Over a period of time, by receiving adequate treatment the parameters started to rise.

Table 2: Serum $\beta$ hcg on respective day of admission in hospital.

\begin{tabular}{|lllllllll|}
\hline & D1 & D3 & D5 & D9 & D12 & D20 & D23 & D28 \\
\hline Bhcg & 7412 & 7565 & 5045 & 2036 & 764 & 476 & 27 & 5 \\
\hline
\end{tabular}

Table 2 shows the trend of $\beta$ hcg monitored in treatment of patient. To start with, as patient was diagnosed scar ectopic pregnancy, received methotrexate for the same.

On day of admission, the patients $\beta$ hcg was 7412, which on further monitoring decreased to less than 5 i.e., nonpregnant level.

\section{DISCUSSION}

Methotrexate has gained its importance in many diseases of gynecology. It was initially used in ovarian cancer and rheumatological diseases like rheumatoid arthritis. Due to its quick action and high efficacy it is widely used in medical disorders. In treating ectopic pregnancy, methotrexate can be given in 2 protocols: single dose, 2 dose and multidose regimen. Single dose methotrexate is administered in $50 \mathrm{mg} / \mathrm{m}^{2}$ on day 1 . Post treatment $\beta$ hcg is measured on $\mathrm{d} 4$ and $\mathrm{d} 7$.

\section{Two dose protocol}

Regimen includes administering $50 \mathrm{mg} / \mathrm{m}^{2} \mathrm{i} . \mathrm{m}$. on $\mathrm{d} 1$ and $\mathrm{d} 4$. Posttreatment $\beta$ hcg is measured on $\mathrm{d} 4$ and $\mathrm{d} 7$.

\section{Multiple doses regimen}

A $1 \mathrm{mg} / \mathrm{kg}$ i.m. methotrexate to be given on $\mathrm{d} 1,3,5,7$ alternate with folinic acid $0.1 \mathrm{mg} / \mathrm{kg}$ i.m. on $\mathrm{d} 2,4,6,8$. HCG is measured on methotrexate dose days and continued till hcg decreases by $15 \%$ at least from previous value. If decrease is $>15 \%$, discontinue $\beta \mathrm{hcg}$ 
administration and monitor $\beta$ hcg weekly till it reaches nonpregnant levels.

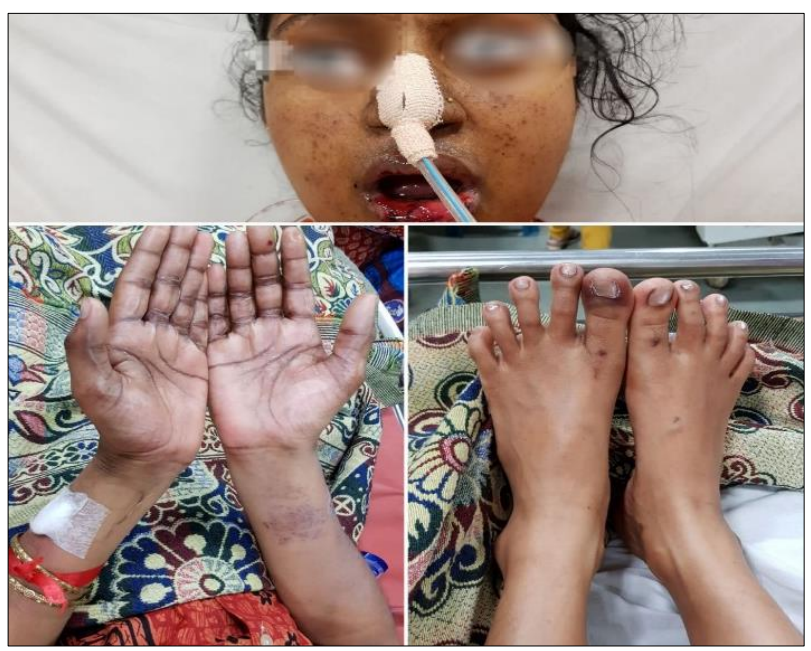

Figure 1: Drug induced Steven Johnson syndrome secondary to methotrexate.

If hcg does not decrease after four doses, surgery may be needed. Intrauterine pregnancy, immunodeficiency, sensitivity to methotrexate, active pulmonary disease, renal disease, active hepatic disease, breastfeeding, ruptured ectopic and hemodynamically unstable patients should not be given methotrexate. ${ }^{1}$ Moreover inability to follow up for hcg, embryonic cardiac activity on USG, ectopic pregnancy $>4 \mathrm{~cm}$ on USG are other contraindications adverse effects of methotrexate are caused by irreversible inhibition of enzyme dihydro pyrolate reductase in purine synthesis and inhibits DNA synthesis repair and cell replication. Also affect actively proliferating tissues like buccal mucosa, skin, bone marrow, respiratory epithelium, intestinal mucosa and trophoblastic tissue. ${ }^{2}$ Medical management of ectopic with methotrexate can be considered for women with confirmed ectopic in hemodynamically stable and ruptured ectopic patients. Women appropriate for medical therapy should be counselled about regular follow-up. Prior to administering methotrexate. It is wise to rule out intrauterine pregnancy and liver, kidney, bone marrow dysfunction. It is important to do a baseline $\beta$ hcg if methotrexate it is being used as treatment option. As baseline $\beta \mathrm{hcg}>5000 \mathrm{mIU} / \mathrm{ml}$ has failure rate of $14.3 \%$ or higher whereas with $\beta$ hcg $<5000 \mathrm{mIU} / \mathrm{ml}^{3}{ }^{3}$ With single dose regimen of methotrexate toxicity is less compared to multi dose regimen. Most common and early adverse effect of methotrexate is hepatotoxicity, pulmonary, bone marrow suppression and nephrotoxicity. Hepatotoxicity is well known toxicity of methotrexate and is limited to development of fatty acid diseases, fibrosis and even cirrhosis. Exact mechanism of developing pancytopenia following methotrexate is unknown, though it can be following decreased renal clearance of methotrexate with age, displacement of methotrexate or its metabolite from plasma proteins, including albumin, impairment of hepatic metabolism of methotrexate may also contribute. ${ }^{4}$

After administering methotrexate, $\beta$ hcg should be serially monitored until nonpregnant levels. Guidelines from American College of Rheumatology, recommend routine peripheral smear and CBC 4 weekly in patients under methotrexate treatment. Exposure to methotrexate for prolonged duration or high doses, increase risk of nephrotoxicity and mucositis. Glucarpidase is carboxypeptidase G2 cleaves methotrexate to nontoxic metabolites and is used in patients with high levels of methotrexate. ${ }^{5}$ The product is still under research trials. Hence it is wise to know the indication, contraindication, and side effects of methotrexate before treating patients. Also, understanding mechanism of action and appropriate dosing schedule will also lead to decreased methotrexate side effects.

This shows the skin lesion accounting for scaling of epidermis on d1 of admission. The patient had blackish spots all over the body with scaling. Lesions around the mouth were severe to cause bleeding. Lesions were seen specifically on face, hands and lower limbs.

Funding: No funding sources Conflict of interest: None declared Ethical approval: Not required

\section{REFERENCES}

1. Practice Committee of the American Society for Reproductive Medicine. Medical treatment of ectopic pregnancy: a committee opinion. Fertil Steril. 2013;100(3):638-44.

2. Chabner BA. Antineoplastic agents. Chapter 61: Cytotoxic Agents Goodman and Gilman's the pharmacological basis of therapeutics; 1996.

3. Menon S, Colins J, Barnhart KT. Establishing a human chorionic gonadotropin cutoff to guide methotrexate treatment of ectopic pregnancy: a systematic review. Fertil Steril. 2007;87(3):481-4.

4. Gutierrez-Ureña S, Molina JF, García CO, Cuéllar ML, Espinoza LR. Pancytopenia secondary to methotrexate therapy in rheumatoid arthritis. Arthritis rheumatism. J Am Col Rheumatol. 1996;39(2):272-6.

5. Schwartz S, Borner K, Müller K, Martus P, Fischer L, Korfel A, et al. Glucarpidase (carboxypeptidase g2) intervention in adult and elderly cancer patients with renal dysfunction and delayed methotrexate elimination after high-dose methotrexate therapy. The Oncol. 2007;12(11):1299-308.

Cite this article as: Lodha $\mathrm{S}$, Mali $\mathrm{K}$. Case report on toxicity of methotrexate in tubal ectopic pregnancy. Int J Reprod Contracept Obstet Gynecol 2020;9:3093-5. 